\title{
Rancang Bangun Sistem Informasi Pengingat Jadwal Pembayaran Angsuran Berbasis Sms Gateway
}

\author{
Desmira $^{1}$, Nur singgih ${ }^{2}$ \\ Program Studi Teknik Informatika - STIMIK NUSAMANDIRI \\ ${ }^{1}$ desmira.dma@bsi.ac.id \\ ${ }^{2}$ nur.singgih.programmer@gmail.com
}

\begin{abstract}
Abstrak - SMS adalah teknologi untuk mengirim pesan. Sistem pengingat jadwal pembayaran angsuran dengan mengirim SMS (Short Message Service) yang masih menggunakan sumber daya manusia atau manual sangat tidak efektif dan tidak efisien, karena berpotensi besar tidak tepat waktu, kurang cepat, waktu pelayanan yang terbatas, dan menambah beban kerja bagi perusahaan. Pelayanan untukmengingatkan jadwal angsuran pelanggan akan jauh lebih efektif dan efisien dengan menggunakan komputer atau otomatis. Model implementasi pengingat jadwal angsuran berbasis SMS Gatewaymemungkinkan komputer dapat mengirimkan SMS kepada pelanggan sebelum tanggal jatuh tempo angsuran dan memberikan informasi yang dibutuhkan pelanggansecara otomatis selama 24 jam non stop. Perangkat lunak yang digunakan untuk sebagai SMS Gateway adalah Gammu.
\end{abstract}

Kata Kunci : SMS, Jadwal Pembayaran, Gammu

\section{PENDAHULUAN}

SMS (Short Message Service) manjadi salah salah mode komunikasi yang sangat populer saat. Fasilitas untuk mengirim dan menerima pesan singkat ini tersedia hampir di seluruh jenis ponsel ini dinilai sangat praktis, murah, dan efisien bagi setiap penggunanya.

Setiap pengguna ponsel pun kemungkinan besar atau bahkan pasti akan membaca setiap SMS yang masuk karena sifat ponsel yang personal. Selain mengirim pesan menggunakan ponsel, SMS juga dapat dikembangkan penggunaannya menggunakan aplikasi berbasis komputer.

Beberapa perusahaan memberikan fasilitas pembayaran angsuran terhadap barang-barang yang dijual. Hal ini merupakan trik bagi perusahaan yang bertujuan untuk memperbesar volume penjualan, karena pada dasarnya setiap konsumen akan lebih tertarik kepada produk yang dijual dengan metode pembayaran angsuran. Pembayaran dengan metode angsuran umumnya dibuat agar menjadi solusi dalam mengatasi permasalahan konsumen dalam hal keringanan beban keuangan dalam membeli suatu produk.

Salah satu permasalahan yang dihadapi baik bagi perusahaan maupun konsumen adalah ketika konsumen lupa jadwal pembayaran angsuran. Kasus seperti ini juga terjadi pada penelitian yang berjudul Aplikasi Reminder Pengobatan Pasien Berbasis SMS Gateway yang menyatakan bahwa :

Tingginya tingkat kesibukan pasien seringkali dapat membuat mereka melewatkan waktu berobat ataupun minum obat. Pada beberapa penyakit, kondisi ini sungguh merugikan, karena dapat membuat pasien harus mengulang proses pengobatan sejak awal. Hal ini tentunya butuh waktu dan biaya kembali. Mengingat tingginya tingkat kesibukan pasien, maka perlu diingatkan hal-hal terkait proses pengobatan supaya tidak terlewatkan[1].

Salah satu penyebab keterlambatan pembayaran angsuran adalah pihak perusahaan yang belum memiliki aplikasi yang mampu mengingatkan setiap konsumen dengan efektif dan efisien ditambah dengan kedisiplinan konsumen serta intensitas kesibukan dari konsumen itu sendiri yang padat sehingga sering lupa ketika telah sampai pada masa jatuh tempo pembayaran angsuran.

\section{METODOLOGI PENELITIAN}

Penelitian dilakukan dalam beberapa tahap, yaitu persiapan, pengumpulan data, analisis data, perancangan aplikasi, pembuatan aplikasi, testing aplikasi, dan diakhiri dengan implementasi aplikasi pada smartphone. Tahap 1 : Persiapan dalam penelitian ini merupakan langkah pertama yang dilakukan untuk ke tehnik selanjutnya, dalam persiapan kebutuhan data dan aplikasi pendukung sampai dengan hasil akhir proses penelitian; Tahap 2 : Pengumpulan data dilakukan dengan cara melakukan studi literatur pustaka ; Tahap 3 : Setelah melakukan studi literatur pustaka dikumpulkan maka data-data tersebut digunakan untuk pembuatan program yang akan dibuat. Analisa data dilakukan untuk bisa mengetahui kebutuhan alat yang akan digunakan dengan menyesuaikan hardware dan software yang akan digunakan; Tahap 4 : Analisa biaya dilakukan untuk mengetahui besaran biaya dalam membangun aplikasi ini, termasuk pembelian perangkat yang dilakukan untuk proses pembuatan aplikasi ini; Tahap 5 : Tahap pemodelan sistem dilakukan guna merancang pemodelan sistem yang akan di bangun dengan menggunakan PHP (Hypertext Preprocessor) sebagai proses sirkulasi aplikasi yang akan dibuat; Tahap 6 : 
Pada tahap ini desain dari aplikasi informasi dilakukan mengenai perencanaan user interface yang baik, kelola manajemen sistem yang baik dan desain aplikasi yang menarik serta bisa dipergunakan dan dipahami oleh pengguna; Tahap 7 : Merupakan tahapan paling akhir yaitu kegiatan pengujian aplikasi informasi yang di bangun, apakah aplikasi yang dibangun sudah optimal, sesuai dengan tujuan dan manfaat yang akan didapat dengan tampilan tatap muka yang menarik dan mudah untuk digunakan.

\section{DASAR TEORI}

\section{Tinjauan Jurnal}

Beberapa penelitian dalam sistem informasi reminder berbasis SMS Gateway yang telah dilakukan antara lain, penelitian yang dilakukan[2] pada penelitiannya yang berjudul Aplikasi SMS Gateway Sebagai Sarana Penunjang Informasi Perpustakaan Pada Sekolah Menengah Pertama Negeri 1 Arjosari[9].

Metode lain diterapkan[3] pada penelitian yang berjudul "Pembuatan Aplikasi SMS Gateway Untuk Informasi Akademik Pada Lembaga Bimbingan Belajar Be Excellent Pacitan".

Dapat disimpulkan bahwa penelitian tersebut diatas memiliki persamaan dengan penelitian yang dilakukan oleh penulis, yaitu membahas mengenai SMS Gateway. Perbedaannya, penulis mengaplikasikan SMS Gateway dalam bidang usaha, khususnya untuk mengefektifkan proses remindering nasabahnya agar pembayaran angsuran tepat waktu. Selain itu nasabah dapat mengetahui informasi status angsuran terkini menggunakan teknologi sistem SMS Gateway.alam penelitian ini, SMS Gateway digunakan sebagai penunjang dalam memberikan informasi akademik dengan lebih cepat dan akurat serta dapat dijadikan sebagai sarana bagi orang tua untuk memantau perkembangan putranya. Penelitian ini meliputi informasi tentang nilai, jadwal dan absensi siswa dengan menggunakan single SMS, broadcast SMS dan auto reply.

\section{SMS (Short Message Service)}

Short Message Service yang lebih dikenal dengan sebutan SMS merupakan sebuah teknologi yang memungkinkan untuk menerima maupun mengirimkan pesan antar telepon bergerak (ponsel)".

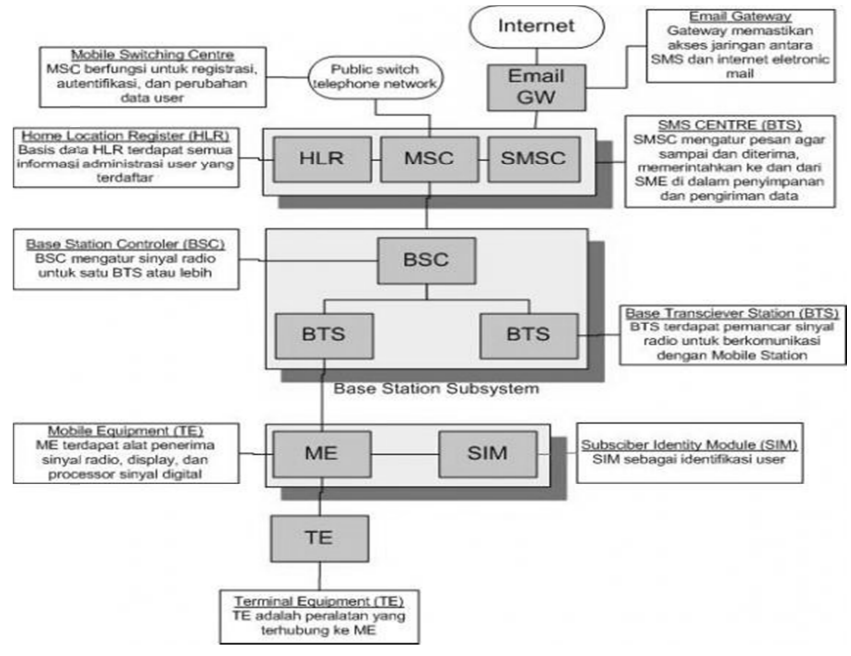

Gambar 1. Arsitektur GSM

\section{Pengenalan SMS Gateway}

SMS Gateway merupakan suatu alat yang fungsinya sebagai sebuah penghubung atau jembatan antara aplikasi atau sistem dengan mobile phone. Di bawah ini disertakan sedikit ilustrasi mengenai penjelasan di atas.

SMS Gateway membolehkan UEA untuk berkomunikasi dengan Telco SMSC (telkomsel, indosat, dan lain-lain) atau SMS platform untuk menghantar dan menerima pesan SMS dengan sangat mudah, Karena SMS Gateway akan melakukan semua proses dan koneksi dengan Telco. SMS Gateway juga menyediakan UEA dengan interface yang mudah dan standar.

SMS Gateway merupakan pintu gerbang bagi penyebaran Informasi dengan menggunakan SMS. Anda dapat menyebarkan pesan ke ratusan nomor secara otomatis dan cepat yang langsung terhubung dengan database nomor-nomor ponsel saja tanpa harus mengetik ratusan nomor dan pesan di ponsel anda karena semua nomor akan diambil secara otomatis dari database tersebut.

\section{PHP (Hypertext Preprocessor)}

PHP atau yang memiliki kepanjangan PHP Hypertext Preprocessor merupakan suatu bahasa pemrograman yang difungsikan untuk membangun suatu website dinamis[6]. PHP bekerja di sisi server (server side scripting) yang dapat melakukan konektifitas pada database yang di mana hal itu tidak dapat dilakukan hanya dengan menggunakan sintak-sintak HTML biasa. PHP banyak dipakai untuk memrogram situs web dinamis, walaupun tidak tertutup kemungkinan digunakan untuk pemakaian lain. Contoh aplikasi lain yang lebih kompleks berupa CMS yang dibangun menggunakan PHP adalah Mambo, Joomla!, Postnuke, Xaraya, dan lain-lain[4]. Para penelitian ini penulis menggunakan PHP versi 5.4.27. Jaringan wireless 
menyediakan mekanisme untuk menemukan station yang dituju dan mengirimkan pesan singkat antara SMSC dengan wireless station. SMS mendukung banyak mekanisme input sehingga memungkinkan adanya interkoneksi dengan berbagai sumber dan tujuan pengiriman pesan yang berbeda[5].

Seperti yang telah disebutkan di atas bahwa PHP adalah aplikasi di sisi server atau dengan kata lain beban kerja ada di server bukan di client. Pada saat browser meminta dokumen PHP, web server langsung menggunakan modul PHP untuk mengolah dokumen tersebut. Jika pada dokumen terkandung fungsi yang mengakses database maka modul PHP menghubungi database server yang bersangkutan. Dokumen yang berformat PHP dikembalikan web server dalam format HTML, sehingga source code PHP tidak tampak di sisi browser [4].

\section{Database}

Penyimpanan data yang fleksibel dan cepat aksesnya sangat dibutuhkan dalam sebuah website yang interaktif dan dinamis[7]. MySQL (My Structure Query Language) adalah sebuah program pembuat database yang bersifat open source dan berjalan di semua platform baik Windows maupun Linux. Selain itu, MySQL juga merupakan program pengakses database yang bersifat jaringan sehingga dapat digunakan untuk aplikasi multi user (Banyak Pengguna).DFD memperlihatkan hubungan fungsional dari nilai yang dihitung oleh sistem, termasuk nilai masukan, nilai keluaran, serta tempat penyimpanan internal[8].

\section{TEKNIK PENGUMPULAN DATA}

Metode pengumpulan data dalam rancang bangun sistem hanya menggunakan Studi Pustaka.Studi pustaka merupakan metode pengumpulan data dengan cara mengumpulkan data-data dari perpustakaan yang mendukung penelitian baik itu dari buku mengenai PHP, MySQL, jurnal, maupun artikel yang membahas tentang SMS gateway, alur jual beli barang metode pembayaran angsuran.

\section{ANALISA KEBUTUHAN}

\section{Hardware (Perangkat Keras)}

Hardware atau perangkat keras yang digunakan dalam penggunaan aplikasi ini dapat berjalan pada spesifikasi :

A. Komputer :
a. Processor Intel Core 2 Duo E7500 (2.93 GHz)
b. Ram $1 \mathrm{~Gb}$
c. Harddisk $160 \mathrm{~Gb}$
d. Monitor 15 inch
e. Keyboard
f. Mouse
g. Kabel Data

\section{h. SIM Card}

i. Modem yang mendukung AT-Command dalam penggunaan sistem ini, penulis menggunakan USB Modem Huawei Model E160E.

B. Handphone yang mendukung fitur SMS.

2. Software (Perangkat Lunak)

Software atau perangkat lunak yang dibutuhkan dalam aplikasi ini yaitu :

a. Sistem operasi windows 7 tipe 32 bit

b. Web Editor Notepad ++ untuk pembuatan PHP sebagai bahasa pemrograman

c. Web Server Xampp versi 1.6.7, MySQL dan PHP Engine

d. Web Browser Mozilla Firefox 3.6 sebagai compiler

e. Gammu 1.25 for windows sebagai jembatan transfer data-data SMS dari

handphone ke komputer dan sebaliknya

3. Kartu SIM

Kartu SIM dari operator manapun yang mendukung layanan SMS dan memiliki pulsa untuk mengirimkan SMS dalam tarif normal.

4. Brainware

Brainware atau sumber daya manusia yang dibutuhkan sebagai administrator sistem informasi pengingat jadwal angsuran nasabah ini, minimal yang mampu mengoperasikan komputer khususnya aplikasi browser.

\section{ANALISA PENGGUNA}

Prosedur dalam pengingat jadwal pembayaran angsuran cicilan nasabah melalui SMS adalah sebagai berikut :

1. Admin login ke dalam sistem dengan cara mengisi username dan password.

2. Admin menginput data transaksi pembelian dan data nasabah.

3. Berdasarkan inputan data transaksi pembelian dan data nasabah maka sistem menghasilkan jadwal pembayaran angsuran cicilan nasabah.

4. Sistem mengidentifikasi jadwal pembayaran angsuran masing-masing nasabah yang belum melakukan pembayaran angsuran cicilan, jika sistem menemukan persamaan tanggal (H-7, H-3, Hari $\mathrm{H}$ dan $\mathrm{H}+1)$ maka sistem akan secara otomatis mengirim SMS pengingat jadwal angsuran kepada nasabah yang bersangkutan.

5. Nasabah dapat mengetahui informasi jadwal angsurannya melalui mengirim pesan (SMS) kepada sistem, sesuai dengan format yang telah ditentukan. Prosedur penerimaan SMS pengingat jadwal angsuran cicilan nasabah yaitu :

a. Nasabah mengirim SMS sesuai dengan format yang telah ditentukan. 
b. Sistem akan melakukan pengecekan pada data nasabah dan data angsuran cicilan nasabah yang tersimpan dalam database sistem.

c. Apabila dalam data angsuran pada sistem terdapat data jadwal angsuran yang diminta oleh nasabah tersebut, maka sistem akan mengirimkan SMS berupa data jadwal angsuran tersebut kepada nasabah yang bersangkutan. Namun, apabila sistem tidak menemukan data jadwal angsuran nasabah yang bersangkutan, maka sistem akan tetap mengirimkan SMS kepada nasabah bahwa tidak terdapat data jadwal yang diminta.

\section{PERANCANGAN}

\section{Rancangan ERD}

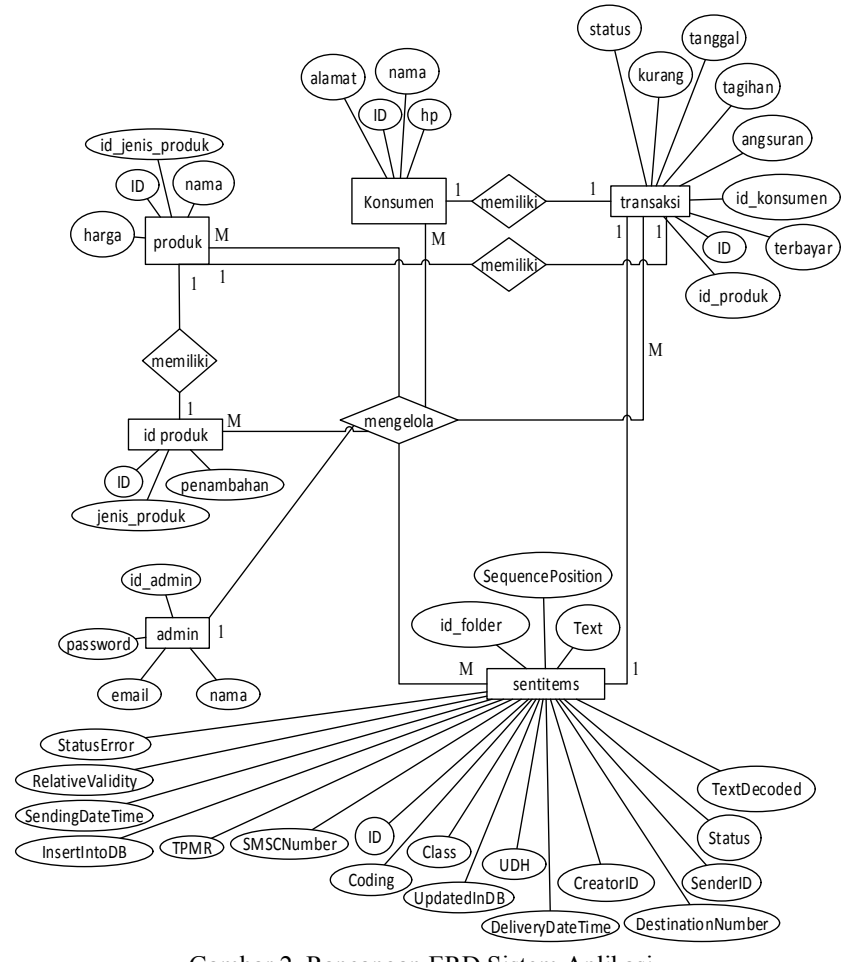

Gambar 2. Rancangan ERD Sistem Aplikasi

\section{Software Architecture}

Arsitektur perangkat lunak merupakan struktur sebuah sistem, yang meliputi elemen perangkat lunak, sifat (property) yang tampak dari elemen itu, serta relasi di antara elemenelemen tersebut. Software arsitektur pada aplikasi ini diilustrasikan pada DFD berikut ini.

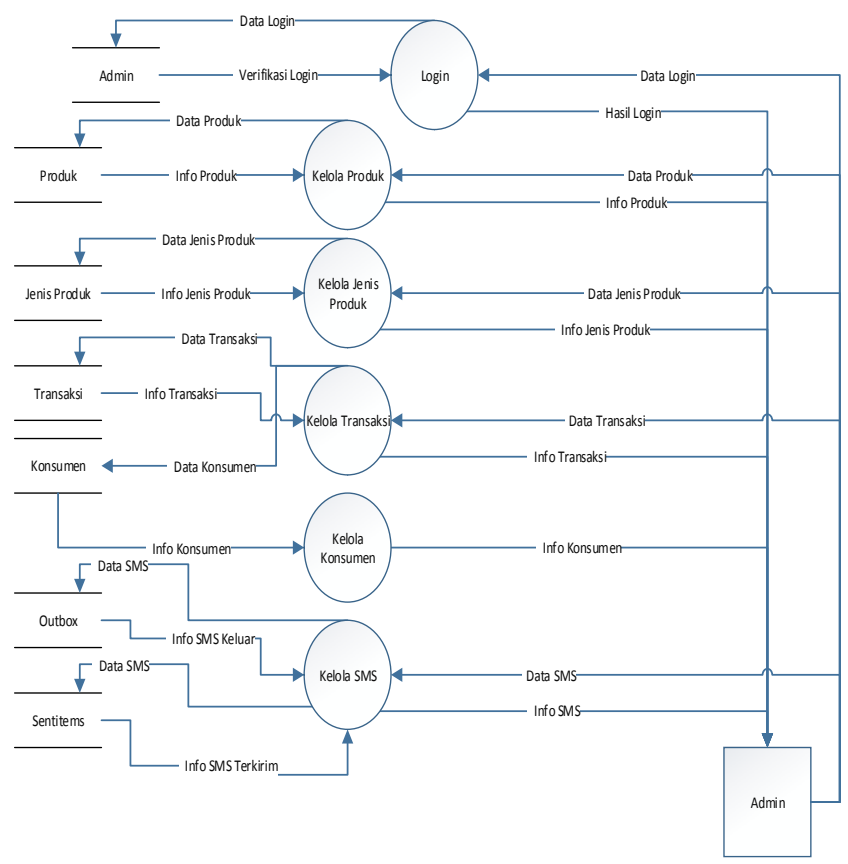

Gambar 3. Desain DFD Sistem Aplikasi

Pada arsitektur perangkat lunak diatas digambarkan bahwa admin mampu mengelola seluruh aktifitas transaksi yang dilakukan. Proses yang dilakukan merupakan aktivitas penambahan data ke database dan dan melakukan view data dari database yang digunakan sebagai informasi utama dalam mengoperasikan aplikasi ini.

Sedangkan software arsitektur terhadap lingkungan luarnya dijelaskan pada gambar berikut ini :

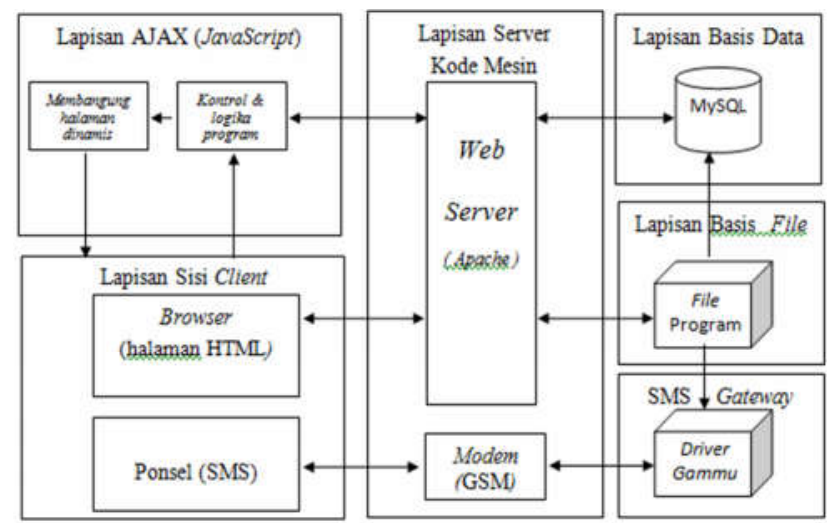

Gambar 4. Arsitektur Aplikasi

Software arsitektur pada lingkungan aplikasi ini memiliki 6 (enam) lapisan. Lapisan Sisi Client sebagai penghubung antara software dan user, baik berupa halaman HTML yang ditampilkan browser maupun berupa SMS yang ditampilkan handphone. Lapisan Ajax (JavaScript) merupakan penghubung 
browser dan server. Lapisan server merupakan penghubung utama komunikasi antar aplikasi. Lapisan basis data merupakan media penyimpanan seluruh data yang diproses aplikasi. Lapisan file sebagai sumber kode program aplikasi. Dan lapisan SMS gateway sebagai driver yang meneruskan data ke sisi server melalui modem.

\section{HASIL DAN PEMBAHASAN}

Berikut fasilitas-fasilitas yang disediakan pada aplikasi seperti terlihat pada gambar tampilan di bawah ini :

a. Menu Utama

Menu utama adalah bagian dari aplikasi yang pertama kali muncul dengan tampilan di bawah ini :

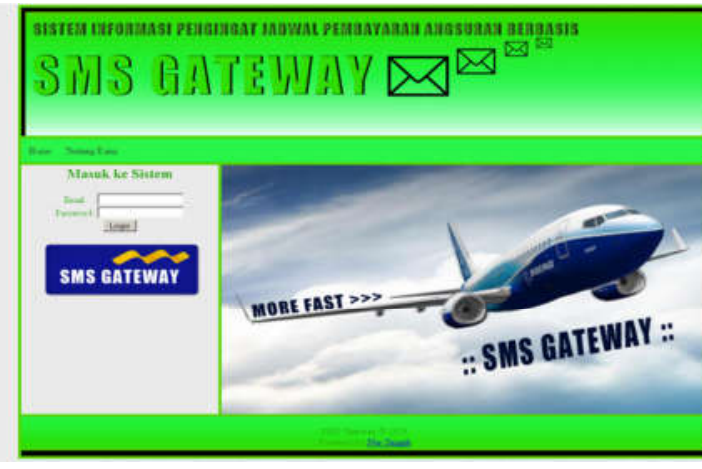

Gambar 5. Halaman Home

b. Menu User interface handphone INFO (titik) Nomor KTP

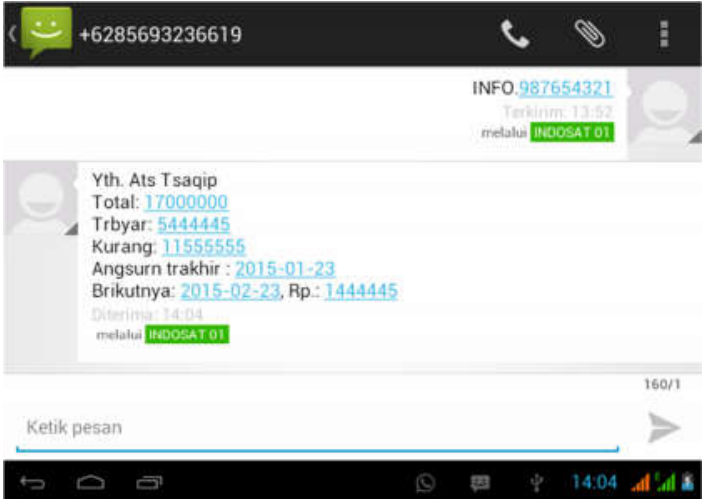

Gambar 6. SMS Balasan INFO (titik) Nomor KTP

c. Pengingat Jadwal Angsuran

1) Jatuh Tempo Pembayaran

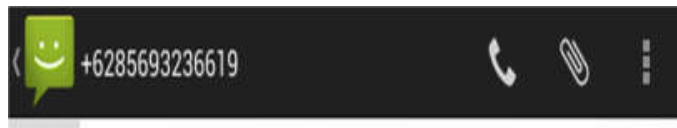

Kpd Yth Nur Singgih, Jatuh Tempo pmbayarn Angs Anda besok tgl 23 Jan 2015, Sbesar Rp 170.000. Abaikan bila tlah mlakukn pmbayarn

4 melalui 30 .

Gambar 7. SMS Balasan Jatuh Tempo Pembayaran

2) Pembayaran Melewati Tanggal Angsuran

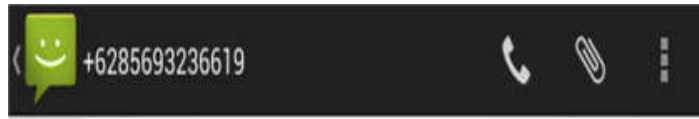

Kpd Yth Nur Singgih, Jtuh Tmpo pmbayarn Angs Anda kmarin tgl 22 Jan 2015 sudah trlewati \& blum mlakukn angsurn, mhon sgra mlakukn 1 pembayarn.

melalui 302

Gambar 8. SMS Balasan Pembayaran Melewati Tanggal Angsuran

3) Ucapan Terima Kasih

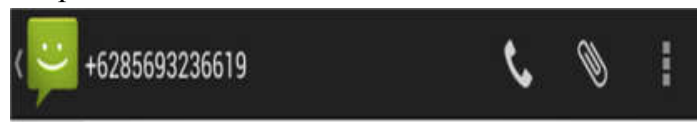

Kpd Yth Nur Singgih, Terimakasih Anda sudah melakukan angsuran sesuai jadwal angsuran.

$\triangle$ melalui 30

Gambar 9. SMS Ucapan Terima Kasih

\section{Testing}

Agar sistem ini dapat berjalan dengan lancar diperlukan pengujian data agar dapat menghasilkan data yang benar-benar akurat. Pengujian perangkat lunak adalah elemen kritis dari jaminan kualitas perangkat lunak dan mempresentasikan kajian pokok dari spesifikasi, desain dan pengkodean. Pengujian pada sistem ini menggunakan white box testing.

\section{White Box Testing}

White box testing adalah metode desain test case menggunakan struktur kontrol desain prosedural untuk mendapatkan test case. Dengan menggunakan metode white box analisis sistem akan memperoleh test case yang :

a) Menjamin seluruh independent path di dalam modul yang dikerjakan sekurang-kurangnya sekali.

b) Mengerjakan seluruh keputusan logical

c) Mengerjakan seluruh loop yang sesuai dengan batasannya 
d) Mengerjakan seluruh struktur data internal yang menjamin validitas

Untuk melakukan proses pengujian Test Case terlebih dahulu dilakukan penerjemahan flowchart kedalam notasi flowgraph (aliran kontrol). Ada beberapa cara istilah saat pembuatan flowgraph, yaitu :

1. Node yaitu lingkaran pada flowgraph yang menggambarkan satu atau lebih perintah prosedural.

2. Edge yaitu tanda panah yang menggambarkan aliran kontrol dari setiap node harus mempunyai tujuan node.

3. Region yaitu daerah yang dibatasi oleh node dan edge dan untuk menghitung daerah diluar flowgraph juga harus dihitung.

4. Predicate node yaitu kondisi yang terdapat pada node dan mempunyai karakteristik dua atau lebih edge lainnya.

5. Cyclomatic complexity yaitu metrik perangkat lunak yang menyediakan ukuran kuantitaf dari kekompleksan logikal program dan dapat digunakan untuk mencari jumlah path dalam suatu flowgraph.

6. Independen path yaitu jalur melintasi atau melalui program dimana sekurang-kurangnya terdapat proses perintah yang baru atau kondisi yang baru.

Rumus-rumus untuk menghitung jumlah independen path dalam suatu flowgraph yaitu :

1. Jumlah region flowrgaph mempunyai hubungan dengan cyclomatic complexity (CC).

2. $\mathrm{V}(\mathrm{G})$ untuk flowgraph dapat dihitung dengan rumus :

a. $\mathrm{V}(\mathrm{G})=\mathrm{E}-\mathrm{N}+2$, dimana :

$\mathrm{E}=$ Jumlah edge pada flowrgaph

$\mathrm{N}=$ Jumlah node pada flowrgaph

b. $\mathrm{V}(\mathrm{G})=\mathrm{P}+1$

Dimana :

$\mathrm{P}=$ Jumlah predicate node pada flowrgaph

Pengujian White Box ini mempunyai tiga langkah (Muhyuzir,1991), yaitu :

1 Menggambar flowgraph yang ditransfer oleh flowchart

2 Menghitung Cylomatic Complexity untuk flowgraph yang telah dibuat

3 Menentukan jalur pengujian dari flowgraph yang berjumlah sesuai dengan cyclomatic complexity yang telah ditentukan. Pengujian white box pada sistem ini sebagai berikut :

a. Flowgraph

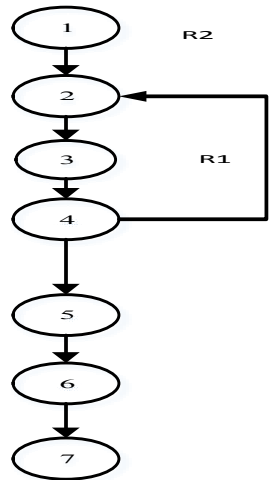

Gambar 10 Proses Tambah Transaksi

b. Keterangan Gambar :

Node 1 : Inisialisasi form, input data transaksi

Node 2 : Input no. KTP calon konsumen

Node 3 : Cari data no. KTP di database, script sebagai berikut :

$\$ \mathrm{~g}=$ mysql_num_rows(mysql_query("selec

$t$ * from konsumen where noKtp='\$_POST[noKtp]"'));

Node 4 : Pilihan ketemu, jika ya, gagal input transaksi karena calon konsumen masih dalam proses angsuran, input no. KTP calon konsumen, script sebagai berikut : if $(\$ g>0)\{?>$

$<$ script type="text/javascript" $>$ alert("Maaf, Konsumen dengan nomor KTP tersebut masih dalam proses angsuran.");

\$("input").val("'); $\$($ "textarea").val("'"); $\$($ ("select").val("'"); \$("span.cekKtp").html("); $</$ script $>$

Node 5 : Jika tidak, input data transaksi, script sebagai berikut :

$<$ ?php \}else $\{$ ?>

$<$ script type $=$ "text/javascript" $>$ ("span.cekKtp").html('<img src="http://'+ urlWeb

+'/images/s_success.png" />'); $</$ script $>$

$<$ ?php \} ?>

Node 6 : Simpan data konsumen pada tabel konsumen dan data transaksi pada tabel transaksi, script sebagai berikut :

mysql_query("insert into konsumen (nama,alamat,hp,noKtp) values ('\$_POST[nama]', 
'\$ POST[alamat]',

'\$ POST[hp]',

'\$_POST[noKtp]')

");

Node 7 : Selesai.

c. Perhitungan :

- $\quad$ Region $(\mathrm{R})$

$=2$

- $\quad \operatorname{Node}(\mathrm{N})$

$=7$

- $\quad \operatorname{Edgen}(\mathrm{E})$

$=7$

- Predicate Node $(\mathrm{P})$

$=1$

1) $\mathrm{V}(\mathrm{G})$

$=\mathrm{E}-\mathrm{N}+2$

$\mathrm{V}(\mathrm{G})$

$=7-7+2=2$

2) $\mathrm{V}(\mathrm{G})$

$=\mathrm{P}+1$

$\mathrm{V}(\mathrm{G})$

$=1+1=2$

3) Cyclomatic Complexity (CC)

$\mathrm{R} 1, \mathrm{R} 2=2$

Jadi cyclomatic complexity untuk flowgraph data transaksi $=2$

d. Langkah Alur :

- $\quad$ Path 1

$: 1-$

2-3-4-5.....

- $\quad$ Path 2

$: 1-$

$$
\text { 2-3-4-5-6-7 }
$$

Berdasarkan hasil pengujian uji coba white box testing diatas dapat disimpulkan bahwa flowchart benar. Hasil uji diatas menunjukkan penerapan metode test case dengan pendekatan white box testing dapat menghasilkan sistem dan proses perulangan pada flowchart di sistem menjadi efektif dan efisien.

Dalam pengujian ini penulis mengambil satu flowchart untuk diuji sebagai wakil dalam sistem ini. Karena cara pengerjaannya sama antara satu flowchart dengan flowchart yang lain.

\section{Black Box Testing}

Black box testing Pengujian black-box sering disebut juga dengan pengujian tingkah laku (behavoiur testing) yang lebih terfokus kepada kebutuhan fungsional dari perangkat lunak, pengujian black-box memungkinkan pembuat perangkat lunak untuk menentukan kondisi yang terjadi untuk suatu masukan yang akan menjalankan semua kebutuhan fungsional.

Jadi dapat disimpulkan bahwa black box testing adalah pengujian yang dilakukan melalui antar muka perangkat lunak atau interface untuk mengetahui apakah kondisi masukan dan keluaran sudah berjalan dengan yang diharapkan.

Pengujian black-box dilakukan untuk menentukan beberapa macam kesalahan, yaitu :

1. Fungsi-fungsi yang tidak benar atau hilang

2. Kesalahan interface

3. Kesalahan dalam struktur data atau database eksternal

4. Kesalahan kinerja

5. Inisialisasi dan kesalahan terminasi
Berikut adalah table black-box testing yang terdapat pada program ini yang telah dibuat oleh penulis :

1. Halaman Login

Tabel 1

Hasil Pengujian Black Box Testing Halaman Login

\begin{tabular}{|c|c|c|c|}
\hline Skenario pengujian & Test case & Output & Validasi \\
\hline $\begin{array}{c}\text { Email tidak di isi dan } \\
\text { password tidak diisi }\end{array}$ & $\begin{array}{c}\text { klik tombol } \\
\text { Login }\end{array}$ & $\begin{array}{c}\text { Tidak dapat mengakses } \\
\text { halaman admin }\end{array}$ & Sesuai \\
\hline $\begin{array}{c}\text { Email di isi dan password } \\
\text { tidak diisi }\end{array}$ & $\begin{array}{c}\text { klik tombol } \\
\text { Login }\end{array}$ & $\begin{array}{c}\text { Tidak dapat mengakses } \\
\text { halaman admin }\end{array}$ & Sesuai \\
\hline $\begin{array}{c}\text { Email tidak di isi dan } \\
\text { password disi }\end{array}$ & $\begin{array}{c}\text { klik tombol } \\
\text { Login }\end{array}$ & $\begin{array}{c}\text { Tidak dapat mengakses } \\
\text { halaman admin }\end{array}$ & Sesuai \\
\hline $\begin{array}{c}\text { Email di isi salah dan } \\
\text { password diisi salah }\end{array}$ & $\begin{array}{c}\text { klik tombol } \\
\text { Login }\end{array}$ & $\begin{array}{c}\text { Tidak dapat mengakses } \\
\text { halaman admin }\end{array}$ & Sesuai \\
\hline $\begin{array}{c}\text { Email di isi benar dan } \\
\text { password diisi benar }\end{array}$ & $\begin{array}{c}\text { klik tombol } \\
\text { Login }\end{array}$ & $\begin{array}{c}\text { Dapat mengakses halaman } \\
\text { admin }\end{array}$ & Sesuai \\
\hline
\end{tabular}

2. Halaman Tambah Produk

Tabel .2

Hasil Pengujian Black Box Testing Halaman Tambah Produk

\begin{tabular}{|c|c|c|c|}
\hline Skenario pengujian & Test case & Output & Validasi \\
\hline $\begin{array}{c}\text { Text Box Nama Produk } \\
\text { tidak diisi }\end{array}$ & $\begin{array}{c}\text { Klik tombol } \\
\text { Simpan }\end{array}$ & $\begin{array}{c}\text { Tidak dapat memproses } \\
\text { simpan data ke database }\end{array}$ & Sesuai \\
\hline $\begin{array}{c}\text { Text Box Harga Produk } \\
\text { tidak diisi }\end{array}$ & $\begin{array}{c}\text { Klik tombol } \\
\text { Simpan }\end{array}$ & $\begin{array}{c}\text { Tidak dapat memproses } \\
\text { simpan data ke database }\end{array}$ & Sesuai \\
\hline $\begin{array}{c}\text { Kategori produk tidak } \\
\text { dipilih }\end{array}$ & $\begin{array}{c}\text { Klik tombol } \\
\text { Simpan }\end{array}$ & $\begin{array}{c}\text { Tidak dapat memproses } \\
\text { simpan data ke database }\end{array}$ & Sesuai \\
\hline Semua Field dilengkapi & $\begin{array}{c}\text { Klik tombol } \\
\text { Simpan }\end{array}$ & $\begin{array}{r}\text { Dapatmemproses simpan data } \\
\text { ke database }\end{array}$ & Sesuai \\
\hline
\end{tabular}

3. Halaman Tambah Jenis Produk

Tabel .3

Hasil Pengujian Black Box Testing Tambah Jenis Produk

\begin{tabular}{|c|c|c|c|}
\hline Skenario pengujian & Test case & Output & Validasi \\
\hline $\begin{array}{c}\text { Text Box Nama Jenis } \\
\text { Produk tidak disi }\end{array}$ & $\begin{array}{c}\text { Klik tombol } \\
\text { Simpan }\end{array}$ & $\begin{array}{c}\text { Tidak dapat memproses simpan } \\
\text { dats ke database }\end{array}$ & Sesuai \\
\hline $\begin{array}{c}\text { Text Box Penambahan } \\
\text { tidak diisi }\end{array}$ & $\begin{array}{c}\text { Klik tombol } \\
\text { Simpan }\end{array}$ & $\begin{array}{c}\text { Tidak dapat memproses simpan } \\
\text { data ke database }\end{array}$ & Sesuai \\
\hline Semua Field dilengkapi & $\begin{array}{c}\text { Klik tombol } \\
\text { Simpan }\end{array}$ & $\begin{array}{c}\text { Dapat memproses simpan data } \\
\text { ke database }\end{array}$ & Sesuai \\
\hline
\end{tabular}

4. Halaman Tambah Transaksi Pembelian 
Tabel 4

Hasil Pengujian Black Box Testing Halaman Tambah Transaksi Pembelian

\begin{tabular}{|c|c|c|c|}
\hline Skenario pengujian & Test case & Ougput & Validasi \\
\hline Text Box Nama tidak diisi & $\begin{array}{c}\text { klik tombol } \\
\text { Simpan }\end{array}$ & $\begin{array}{c}\text { Tidak dapat memproses simpan } \\
\text { data ke database }\end{array}$ & Sesuai \\
\hline $\begin{array}{c}\text { Text Area Alamat tidalk } \\
\text { diisi }\end{array}$ & $\begin{array}{c}\text { klik tombol } \\
\text { Simpan }\end{array}$ & $\begin{array}{c}\text { Tidak dapat memproses simpan } \\
\text { data ke database }\end{array}$ & Sesuai \\
\hline Text Box No HP tidak diisi & $\begin{array}{c}\text { klik tombol } \\
\text { Simpan }\end{array}$ & $\begin{array}{c}\text { Tidak dapat memproses simpan } \\
\text { data ke database }\end{array}$ & Sesuai \\
\hline Pembelian tidak dipilih & $\begin{array}{c}\text { klik tombol } \\
\text { Simpan }\end{array}$ & $\begin{array}{c}\text { Tidak dapat memproses simpan } \\
\text { data ke database }\end{array}$ & Sesuai \\
\hline Text Box DP tidak diisi & $\begin{array}{c}\text { klik tombol } \\
\text { Simpan }\end{array}$ & $\begin{array}{c}\text { Tidal dapat memproses simpan } \\
\text { data ke database }\end{array}$ & Sesuai \\
\hline Text Box Diangsur tidak & $\begin{array}{c}\text { klik tombol } \\
\text { Simpan }\end{array}$ & $\begin{array}{c}\text { Tidak dapat memproses simpar } \\
\text { data ke database }\end{array}$ & Sesuai \\
\hline
\end{tabular}

5. Halaman Kirim Pesan Single

Tabel .5

Hasil Pengujian Black Box Testing Halaman Kirim Pesan Single

\begin{tabular}{|c|c|c|c|}
\hline Skenario pengujian & Test case & Output & Validasi \\
\hline TextArea Pesan tidak diis: & $\begin{array}{c}\text { Klik tombol } \\
\text { Kirim }\end{array}$ & $\begin{array}{c}\text { Tidak dapat memproses kirim } \\
\text { pesan }\end{array}$ & Sesuai \\
\hline Text Box No HP tidak diis: & $\begin{array}{c}\text { Klik tombol } \\
\text { Kirim }\end{array}$ & $\begin{array}{c}\text { Tidak dapat memproses kirim } \\
\text { pesan }\end{array}$ & Sesuai \\
\hline Semua Field dilenglapi & $\begin{array}{c}\text { Klik tombol } \\
\text { Kirim }\end{array}$ & Dapat memproses kirim pesan & Sesuai \\
\hline
\end{tabular}

6. Halaman Kirim Pesan Group

Tabel 6

Hasil Pengujian Black Box Testing Halaman Kirim Pesan Single

\begin{tabular}{|c|c|c|c|}
\hline Skenario pengujian & Test case & Ouput & Validasi \\
\hline TextArea Pesan tidak diis: & $\begin{array}{c}\text { Klik tombol } \\
\text { Kirim }\end{array}$ & Data / Field Kosong Enor & Sesuai \\
\hline Group tidak dipilih & $\begin{array}{c}\text { Klik tombol } \\
\text { Kirim }\end{array}$ & Data / Field Kosong Error & Sesuai \\
\hline Semus Field dilengkapi & $\begin{array}{c}\text { Klik tombol } \\
\text { Kirim }\end{array}$ & $\begin{array}{c}\text { Semua Data Field Tersimpan } \\
\text { dan tampil otomatis }\end{array}$ & Sesuai \\
\hline
\end{tabular}

\section{SIMPULAN}

a. Sistem pengingat jadwal pembayaran angsuran nasabah untuk mengingatkan nasabahnya membayar angsuran masih jarang digunakan.

b. Upaya dalam menanggapi kelancaran pembayaran angsuran biasanya hanya ada surat yang bersifat teguran kepada nasabah saat sudah melewati jatuh tempo, dan itu merupakan penanganan keterlambatan, bukan upaya pencegahan keterlambatan pembayaran angsuran.
C. Penelitian ini telah menghasilkan aplikasi pengingat jadwal pembayaran angsuran nasabah berbasis SMS gateway yang memiliki fitur SMS reminder dan SMS autorespond.

d. Aplikasi pengingat jadwal pembayaran angsuran nasabah berbasis SMS gateway yang dihasilkan dengan fitur SMS reminder berfungsi untuk mengingatkan jadwal pembayaran angsuran nasabah sesuai dengan ketentuan, yaitu pada tujuh dan tiga hari sebelum tanggal jatuh tempo angsuran serta pada hari tanggal jatuh tempo, selain itu juga memberitahukan denda dan menyampaikan penghargaan atau ucapan terima kasih kepada nasabah yang telah membayar angsuran atau melunasi hutang, yaitu satu hari setelah tanggal jatuh tempo angsuran nasabah. Sedangkan SMS gateway dengan fitur SMS autorespond berfungsi untuk memberikan balasan SMS otomatis berupa informasi mengenai jadwal angsuran nasabah.

\section{DAFTAR PUSTAKA}

1. Wilieyam dan Gisela Nina Sevani. 2013. Aplikasi Reminder Pengobatan Pasien Berbasis SMS Gateway. Jakarta : Jurnal ilmiah Vol. 7, No. 1 Mei 2013: 12-20.

2. Nurlaela, Fetty. 2013. Aplikasi Sms Gateway Sebagai Sarana Penunjang Informasi Perpustakaan Pada Sekolah Menengah

3. Liatmaja, Rizka dan Bambang Eka Purnama. 2013. Pembuatan Aplikasi Sms Gateway Untuk Informasi Akademik Pada Lembaga Bimbingan Belajar Be Excellent Pacitan. ISSN: 2302-5700. Pacitan: Jurnal ilmiah Vol. 1, No. 1 Juli $2013: 1-7$

4. Anugrah, Nurah. 2012. PHP Adalah. Diambil dari : www.nurahratu.com/tutorial/web-design/joomla/merubahfavicon/203-phpadalah.html. (19 November 2014)

5. Pakpahan, Hombar. 2012. Pengertian SMS. Diambil dari : www.ombar.net/2009/09/pengertian-sms.html. November 2014)

6. Saputra, Agus. 2011. Step By Step Membangun Aplikasi SMS dengan PHP dan MySQL. Jakarta : PT. Elex Media Komputindo.

7. Jogiyanto, HM, 2005, Analisis dan Desain Sistem Informasi, Yogyakarta : Penerbit ANDI.

8. Nugroho, Bunafit., 2004, PHP dan MySQL Dengan Editor Dreamweaver Mx, Yogyakarta : Andi.

9. Pertama Negeri 1 Arjosari. ISSN: 2302-5700. Arjosari : Jurnal ilmiah Vol. 2, No. 4 Oktober $2013: 20-25$ 